\title{
Surface Properties and Osteoblastic Cytocompatibility of Two Blasted and Acid-Etched Titanium Implant Systems with Distinct Microtopography
}

\author{
Pedro Mesquita ${ }^{1}$, Pedro de Sousa Gomes ${ }^{2}$, Paula Sampaio ${ }^{3}$, Gintaras Juodzbalys ${ }^{4}$, Américo Afonso ${ }^{1}$, \\ Maria Helena Fernandes ${ }^{2}$ \\ ${ }^{1}$ Laboratório de Anatomia e Histologia Dentária, Faculdade de Medicina Dentária, Universidade do Porto, Portugal. \\ ${ }^{2}$ Laboratório de Farmacologia e Biocompatibilidade Celular, Faculdade de Medicina Dentária, Universidade do Porto, \\ Portugal. \\ ${ }^{3}$ Instituto de Biologia Molecular e Celular, Universidade do Porto, Porto, Portugal. \\ ${ }^{4}$ Department of Maxillofacial Surgery, Medical Academy, Lithuanian University of Health Sciences, Kaunas, Lithuania.
}

\author{
Corresponding Author: \\ Maria Helena Fernandes \\ Laboratory of Pharmacology and Cellular Biocompatibility \\ Faculty of Dental Medicine, University of Porto \\ Rua Dr. Manuel Pereira da Silva \\ 4200-393 Porto \\ Portugal \\ E-mail: mhfernandes@fmd.up.pt
}

\begin{abstract}
Objectives: The aim of this study is to compare two commercially available screw-type sandblasted and acid-etched (SLA) Ti implant systems from Eckermann Laboratorium S.L., with similar geometry and distinct microtopography, regarding surface properties and osteoblastic cytocompatibility.

Material and Methods: Implant I (referred as a conventional SLA system) and Implant II (a system patented as Eckcyte ${ }^{\circledR}$ ) were characterized for macro and microtopograpphy, surface roughness and chemical composition. For the cytocompatibility studies, human bone marrow osteoblastic cells were seeded over the implants' surface, and the cell response was assessed for cell adhesion and proliferation, alkaline phosphatase (ALP) activity and matrix mineralization.

Results: Implant I presented a rough surface with irregularly shaped and sized cavities among flatter-appearing areas, whereas Implant II exhibited a homogeneous rough microporous surface. Compared to Implant I, Implant II presented higher Ra values $(0.8$ [SD 0.008] $\mu \mathrm{m}$ and 1.21 [SD 0.15] $\mu \mathrm{m}$, respectively, $\mathrm{P}<0.05)$ and also increased values of Rz, Rt and Rsm, a more negative value of Rsk, and similar RKu values. XPS showed the expected presence of Ti, O, C and N; Al, Si, F, P and Ca were detected in low concentrations. Implant II exhibited significantly lower Al levels. Both implants supported the adhesion, proliferation and differentiation of osteoblastic cells. Implant II showed a thicker fibrilar cell layer and an earlier onset and more abundant matrix mineralization.

Conclusions: The homogeneous rough and microporous surface of Implant II is most probably a main contributor for its improved cell response.
\end{abstract}

Keywords: dental implants; surface properties; bone marrow; osteoblasts; differentiation cell; cell culture.

Accepted for publication: 29 March 2012

To cite this article:

Mesquita P, Gomes PD, Sampaio P, Juodzbalys G, Afonso A, Fernandes MH. Surface Properties and Osteoblastic Cytocompatibility of Two Blasted and Acid-Etched Titanium Implant Systems with Distinct Microtopography.

J Oral Maxillofac Res 2012 (Jan-Mar);3(1):e4

URL: http://www.ejomr.org/JOMR/archives/2012/1/e4/v3n1e4ht.pdf

doi: $10.5037 /$ jomr.2012.3104 


\section{INTRODUCTION}

Titanium (Ti) screw-shaped dental implants are biocompatible, have high corrosion resistance, are lightweight and durable, and can be easily prepared in many different shapes and textures without affecting their biocompatibility $[\underline{1}, 2]$.

Ti surface topography is an essential feature in implant design, but the optimal surface texture remains to be established $[\underline{3}, \underline{4}]$, due to the difficulty in correlating surface properties with clinical results $[\underline{5}, \underline{6}]$. In addition to the wide range of possibilities in creating complex topographies, other factors in implant design, namely geometry, i.e. distance between peaks, curvature of the valleys and relative distribution of flat and smooth regions, are also relevant for the short and long-term clinical outcome [1]. Also, other aspects not related with topography, material itself or fabrication process may significantly affect the clinical performance. Each patient exhibits a specific answer to a particular implant depending on bone characteristics, patient's health status and surgical technique [ $[\underline{6}, \underline{7}]$. However, studies performed on animals and representative cell culture systems continually provide important information concerning the relevance of surface properties and biological performance of the implants [8-10].

In this context, a wide variety of studies have shown that early fixation and long-term stability is improved by a high roughness profile, compared to a smooth surface, due to the mechanical interlocking between the implant surface and bone ingrowth [11]. It was reported that surface roughness in the range of $1-10 \mu \mathrm{m}$ maximizes the bone/implant interlocking $[\underline{3}, 12]$. However, a high roughness appears to be associated with the risk of increased peri-implantitis and ionic leakage [13]. Albrektsson and Wennerberg have shown that a moderate roughness of $1-2 \mu \mathrm{m}$ may limit this process and improve implant performance [2].

Microtopographic features were also found to play a decisive role on the biological response to dental implants [14-16]. Discontinuities or curvatures associated with microtopographic features seem to induce local changes in the surface free energy, thus modifying the amount and type of adsorbed proteins that can modulate the local cellular response [16]. In vitro studies revealed that topographic properties were found to affect several cellular events, including cell attachment, alignment, direction of proliferation, growth rate and metabolism, and thus influence the osseointegration process $[14,15,17]$. A theoretical approach suggested that the ideal surface should be covered with hemispherical pits approximately $1.5 \mu \mathrm{m}$ in depth and $4 \mu \mathrm{m}$ in diameter [18].
Eckermann Laboratorium S.L. (Alicante, Spain) developed two implant systems with different surfaces. One system is referred by the manufacturer as a conventional SLA surface. The other system, which was launched later and patented as Eckcyte ${ }^{\circledR}$, is claimed to present improved surface properties. It is important to examine those surface characteristics and osteoblastic cytocompatibility of these two implant systems, in order to relate and compare the two parameters.

The aim of this study is to compare two commercially available screw-type sandblasted and acid-etched (SLA) Ti implant systems from Eckermann Laboratorium S.L., with similar geometry and distinct microtopography, regarding surface properties and osteoblastic cytocompatibility.

\section{MATERIAL AND METHODS Ti Implants}

The implants tested in this study were two commercially screw-type sandblasted and acid- etched Ti implant systems manufactured by Eckermann Laboratorium S.L. (Alicante, Spain). The implants were sandblasted with alumina $\left(\mathrm{Al}_{2} \mathrm{O}_{3}\right)$ particles, followed by an acid etching treatment involving $\mathrm{HCl}, \mathrm{H}_{2} \mathrm{SO}_{4}$ and $\mathrm{HF}$ solutions, and differ on the experimental conditions of the blasting and the etching protocols, however, details of the manufacturing process were not available. The implants will be referred as Implant I (the implant mentioned as a conventional SLA system) and Implant II (the system patented as Eckcyte $^{\circledR}$ ). Implants I and II were $3.0 \mathrm{~mm}$ in diameter and 8 and $13 \mathrm{~mm}$ in length, respectively. The implants were removed from their sterile package just before surface and cytocompatibility studies.

\section{Surface characterization of Ti implants}

The surface of the threaded parts of Implants I and II was assessed for macro and microtopography, surface roughness and chemical composition.

\section{Macro and microtopography}

Morphology and texture were assessed by scanning electron microscopy (SEM) with a JEOL JSM 6301F scanning electron microscope equipped with an X-ray energy dispersive spectroscopy (EDS) microanalysis capability (Voyager XRMA System, Noran Instruments, Madison, WI, USA). Implants were fixed to an aluminium sample holder on a conducting carbon surface. Observation was performed at $15 \mathrm{kV}$, and magnification varied from $\times 30$ to $\times 2000$. 
Surface roughness and optical profilometry

Roughness measurements were performed with a T8000 Hommel profiler (Hommel AG, Hamburg, D). The measured length was $1.00 \mathrm{~mm}$, cut-off was 0.08 $\mathrm{mm}$, the radius tip was $5 \mathrm{~mm}$, and the filter used was M1 (according to ISO 11562). The measurements were performed in randomly selected regions; in each region, three measurements were done. The implants were assessed for Ra, Rt, Rz, Rsm, Rku and Rsk.

The three-dimensional-surface roughness was assessed with an optical profiler coupled to a confocal laser scanning microscope (CLSM, Leica SP2 AOBS SE, Leica Microsystems, Germany). The images were taken on the peak and on the valley of the thread, and were worked out with a specific software (Leica Microsystems Heidelberg GmbH, 2.61 Build 1538 LCS Lite, Leica Microsystems, Germany).

\section{Chemical composition}

The chemical composition was analysed by X-ray photoelectron spectroscopy (XPS, ESCALAB 200A, VG Scientific, UK) by using an Al source operated at $15 \mathrm{KV}$ and $300 \mathrm{~W}$ and a pressure lower than $10^{-6} \mathrm{~Pa}$. The area of the surface analysed was approximately $10 \mathrm{~mm}^{2}$. This analysis allows for the identification of residual contamination and for the semi-quantification of the composition of the external layers of the surface. The following peaks were considered: $\mathrm{C} 1 \mathrm{~s}, \mathrm{O} 1 \mathrm{~s}$, Ti 2p, Al 2p, N 1s, Si 2p, F 1s, P 2p, Ca 2p and Pb 4f.

A qualitative assessment of the chemical composition of the implants' surface was also performed by EDS (Voyager XRMA System, Noran Instruments, Madison, WI, USA) coupled to a JEOL JSM 6301F scanning electron microscope.

\section{Osteoblastic cytocompatibility of Ti implants}

Human bone marrow cell cultures

Cytocompatibility studies were performed with human bone marrow osteoblastic cell cultures. Bone marrow was obtained from orthopaedic surgery procedures, after Local Ethical Committee approval and patient informed consent. Bone marrow was cultured in $\alpha$-Minimal Essential Medium ( $\alpha$-MEM) containing $10 \%$ foetal bovine serum, $50 \mu \mathrm{g} / \mathrm{ml}$ ascorbic acid, 100 $\mathrm{IU} / \mathrm{ml}$ penicillin, $2.5 \mu \mathrm{g} / \mathrm{ml}$ streptomycin and $2.5 \mu \mathrm{g} / \mathrm{ml}$ fungizone, at $37{ }^{\circ} \mathrm{C}$ in a humidified atmosphere of $5 \%$ $\mathrm{CO}_{2}$ in air.

Primary cultures were maintained until near confluence (10 - 15 days) and, at this stage, adherent cells were enzymatically released (trypsin-EDTA solution). Second-passage cells were seeded $\left(5 \times 10^{4} \mathrm{cell} / \mathrm{cm}^{2}\right)$ over the surface of the implants. Seeded implants were cultured for 30 days in the presence of $50 \mu \mathrm{g} / \mathrm{ml}$ ascorbic acid, $10 \mathrm{mM} \beta$-glycerophosphate and $10 \mathrm{nM}$ dexamethasone.

Colonized implants were evaluated for cell adhesion, pattern of cell growth, alkaline phosphatase (ALP) activity and matrix mineralization.

\section{Alkaline phosphatase activity (ALP)}

The colonized materials were treated with $0.1 \%$ triton in water (to lyse the cell layer) and the cell lysates were evaluated for ALP activity, at days 7, 14, 21, 24 and 28. ALP was assayed by the hydrolysis of p-nitrophenyl phosphate in alkaline buffer solution, $\mathrm{pH} 10.3,30 \mathrm{~min}$ at $37^{\circ} \mathrm{C}$, and colorimetric determination of the product (p-nitrophenol) at $\lambda=405$ $\mathrm{nm}$, in an ELISA plate reader (Synergy HT, Biotek, Vermont, USA). Enzyme activity was normalized to total protein content, at the same time-points. The total amount of protein was assayed by the Lowry's method with bovine serum albumin used as a standard. ALP activity is expressed as nanomoles of p-nitrophenol produced per min per $\mu \mathrm{g}$ of protein $\left(\mathrm{nmol} \cdot \mathrm{min}^{-1} / \mu \mathrm{g}\right.$ protein).

\section{Scanning electron microscopy (SEM) observation}

SEM was performed at 3 and $24 \mathrm{~h}$ and 28 days. Seeded implants were fixed $(1.5 \%$ glutaraldehyde in $0.14 \mathrm{M}$ sodium cacodylate buffer, $\mathrm{pH}$ 7.3, $10 \mathrm{~min}$ ), dehydrated in graded alcohols, critical-point dried, sputter-coated with gold and analysed in a JEOL JSM 6301F scanning electron microscope equipped with a X-ray energy dispersive spectroscopy (EDS) microanalysis capability (Voyager XRMA System, Noran Instruments, Madison, WI, USA).

Concentration of ionized calcium in the culture medium

Culture medium from the cultured implants was collected every 2 - 3 days (and cultures were refed with fresh medium). Analysis of ionized calcium $\left(\mathrm{Ca}_{\mathrm{i}}\right)$ content in the culture medium was conducted using Sigma Diagnostics Kit (Sigma-Aldrich Corporation, St. Louis, MO, USA) procedure number 587. Results were expressed as millimoles of $\mathrm{Ca}_{\mathrm{i}}$ per litre of medium (mmol/l).

\section{Statistical analysis}

Results regarding surface characterization and cytocompatibility studies were obtained from three independent experiments. In each experiment, and 
for each time-point, 6 implants were characterized. In the cytocompatibility studies, the three experiments were performed with cell cultures established from different donors. Quantitative data are presented as mean (SD). Groups of data were evaluated using oneway analysis of variance (ANOVA) and Bonferroni procedure for post-hoc comparison using SPSS (Apache software foundation, version 15.0). Values of $\mathrm{P} \leq 0.05$ were considered significant.

\section{RESULTS}

\section{Surface characterization \\ Macro and microtopography}

Implant I and Implant II contained 6 and 11 threads,
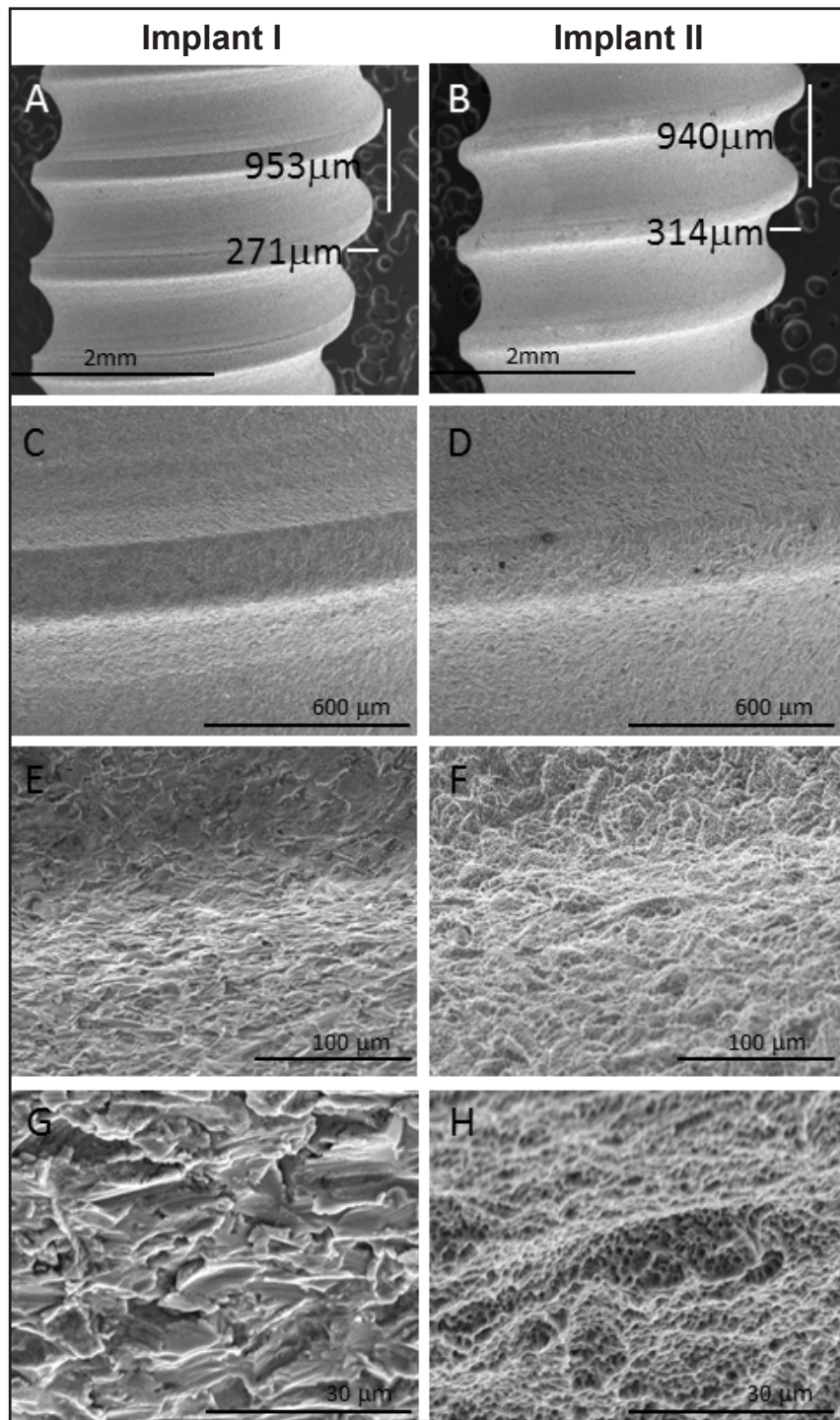

Figure 1. SEM images of the geometry (A, B) and surface topography at low $(\mathrm{C}, \mathrm{D})$ and high $(\mathrm{E}-\mathrm{H})$ magnification of the threaded regions of Implants I and II. Implants presented a similar geometry, but a distinct microtopography. Implant I presented an irregularly rough morphology with different sized cavities and flat areas and Implant II exhibited a relatively homogeneous microporous surface. respectively, and a similar spacing and peak-valley distance (Figure 1A, B). At low magnification SEM images, both implants showed a relatively homogeneous appearance (Figure 1A - D). At high magnification (Figure 1E - H), Implant I presented a rough surface with irregularly shaped and sized cavities among flatterappearing areas of various sizes. Implant II showed a regular rough surface with a relatively homogeneous topography, displaying abundant and randomly distributed rounded pits with an average diameter of $1-4 \mu \mathrm{m}$.

\section{Surface roughness}

The roughness profiles of the implants (Figure 2A) showed that Implant II exhibited higher amplitude of peak to valley distances, compared to Implant I. Regarding the roughness parameters (Figure 2B), Implant II presented Ra values higher than Implant I (1.21 [SD 0.15] $\mu \mathrm{m}$ and 0.8 [SD 0.08] $\mu \mathrm{m}$, respectively.) Also, increased values of Rz, Rt and Rsm were found on Implant II. Rsk was more negative on Implant II, but the two implants showed similar RKu values.

Observation of the three-dimensional-topometric images of the implants' surface (Figure 3) showed that Implant I displayed a higher variation in the peak protuberances, compared to Implant II.

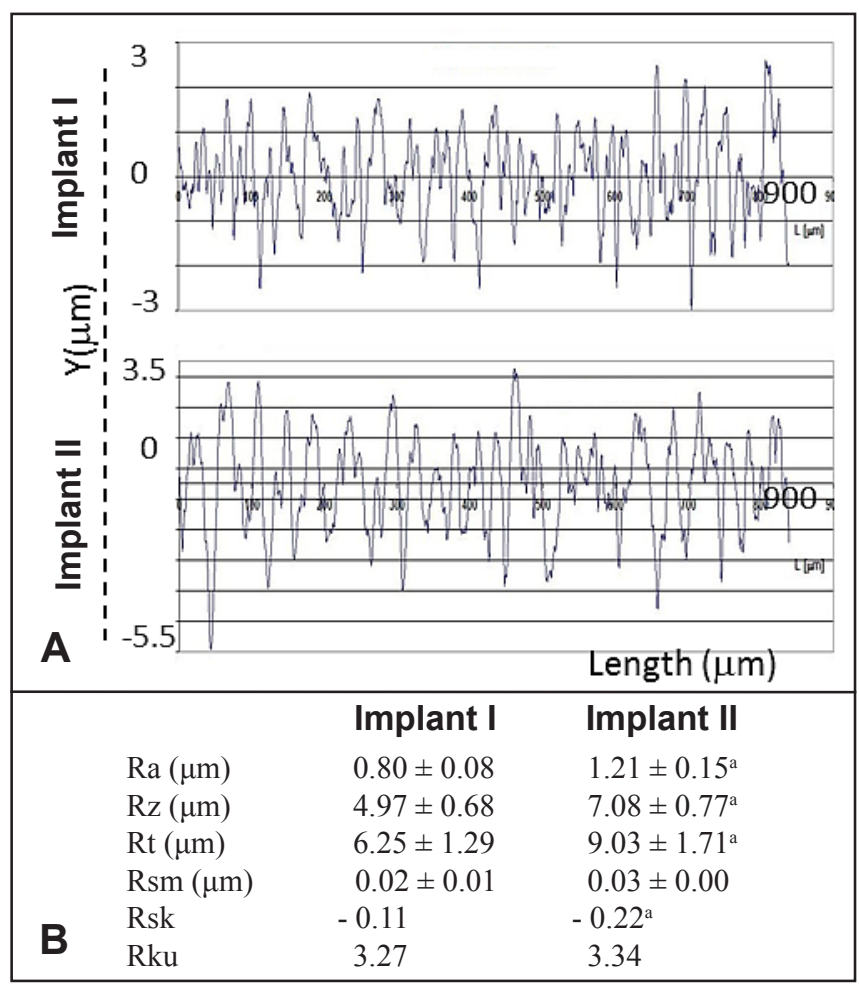

Figure 2. Roughness profiles (A) and parameters (B) of the threaded regions of Implants I and II. Implant II showed higher amplitude of peak to valley distances (A) and higher values of Ra, Rz, Rt, Rsm and Rsk (B).

${ }^{a}$ Significantly different from Implant I. 


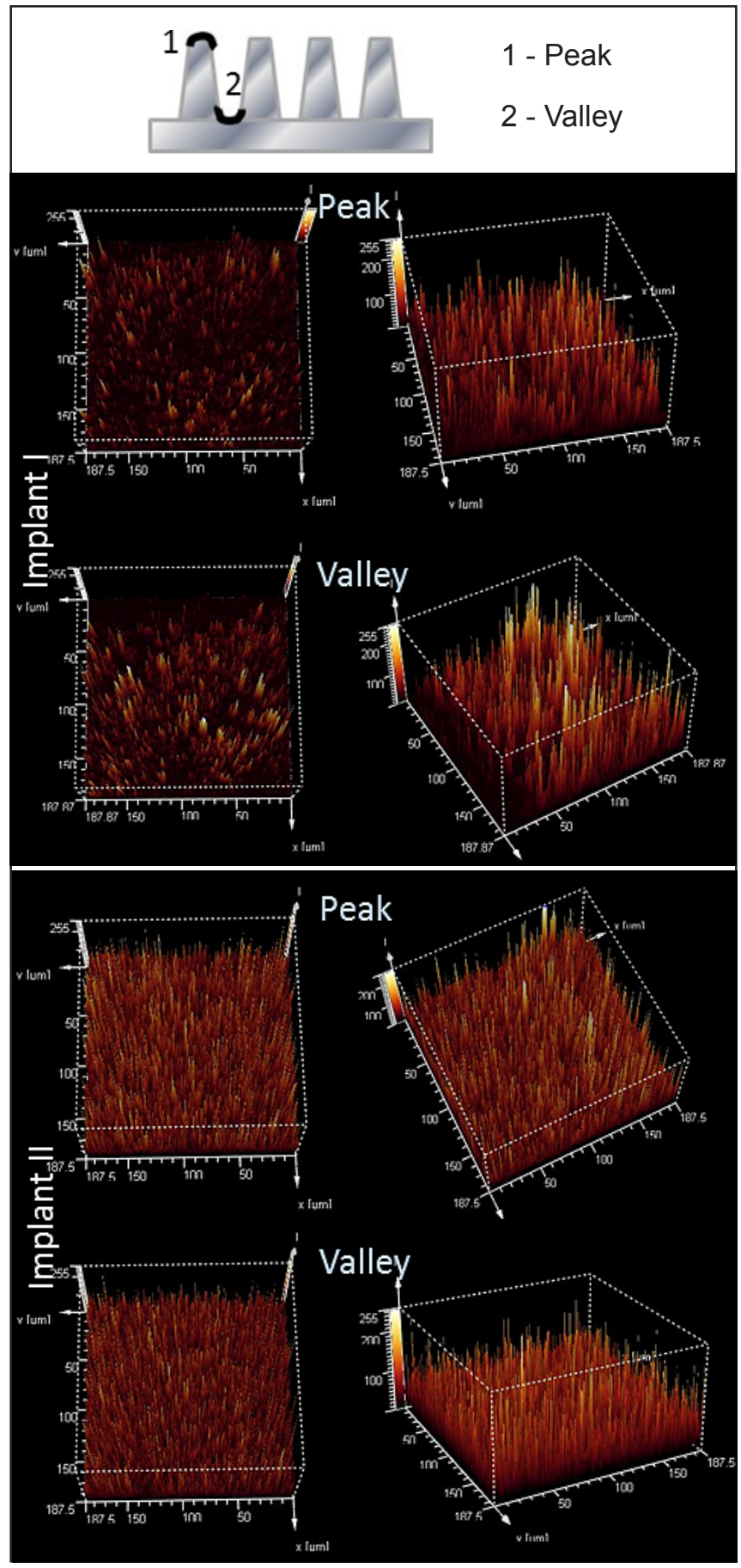

Figure 3. Three-dimensional-optical profilometric profiles of the threaded regions of Implants I and II. Evidence of a more homogeneous rough surface was noticed for Implant II.

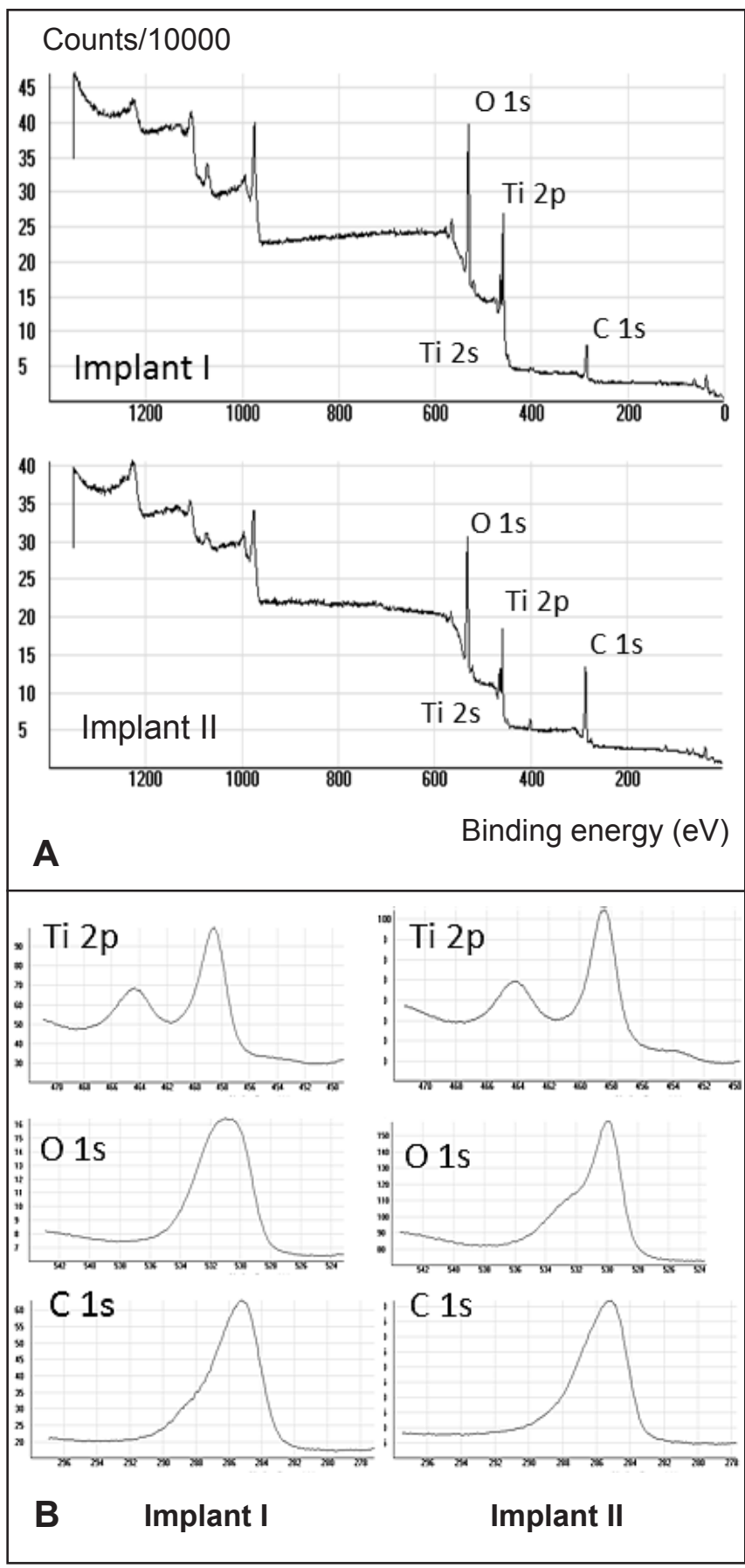

Figure 4. XPS survey spectra of the threaded regions of Implants I and II (A) and detailed spectra of Ti, O and C elements. The Ti $2 p$ doublet and the $\mathrm{O} 1 \mathrm{~s}$ peak reflected the $\mathrm{TiO}_{2}$ layer, and the $\mathrm{C} 1 \mathrm{~s}$ peak indicates an organic contamination.

Table 1. Semi-quantitative XPS analysis of the Ti implants (at \%)

\begin{tabular}{cccccccccc}
\hline & C 1s & O 1s & Ti 2p & Al 2p & N 1s & Si 2p & F 1s & P 2p & Ca 2p \\
\hline Implant I & $45.13(3.47)$ & $35.74(2.21)$ & $8.28(0.72)$ & $5.13(0.72)$ & $3.14(0.29)$ & $1.36(0.15)$ & $0.55(0.08)$ & $0.50(0.07)$ & $0.17(0.03)$ \\
Implant II & $60.66(7.40)^{\mathrm{a}}$ & $26.79(4.93)$ & $8.06(1.86)$ & $1.02(0.56)^{\mathrm{a}}$ & $1.79(0.22)^{\mathrm{a}}$ & $0.75(0.15)^{\mathrm{a}}$ & $0.21(0.06)^{\mathrm{a}}$ & $0.18(0.02)^{\mathrm{a}}$ & $0.56(0.16)^{\mathrm{a}}$ \\
\hline
\end{tabular}

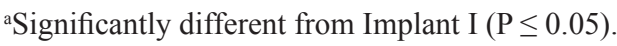

$\mathrm{M}(\mathrm{SD})=$ mean (standard deviation) . 


\section{Chemical composition}

XPS representative spectra and results of the elemental atomic percentage (Figure 4 and Table 1, respectively) showed the presence of $\mathrm{Ti}$ ( $\mathrm{Ti} 2 \mathrm{p}$ doublet, at $\sim 459 \mathrm{eV}$ ), $\mathrm{O}(\mathrm{O} 1 \mathrm{~s}$ peak, at $\sim 531 \mathrm{eV}), \mathrm{C}(\mathrm{C} 1 \mathrm{~s}$, at $\sim 285 \mathrm{eV})$ and $\mathrm{N}$ in higher percentages; other elements were present in significantly lower concentrations, i.e. Al, $\mathrm{Si}, \mathrm{F}, \mathrm{P}$ and $\mathrm{Ca}$. Implants I and II had similar percentages of Ti and $\mathrm{O}$ (Table 1). Regarding the elements found in low percentages, the most evident difference between the two implants was the significantly lower percentage of $\mathrm{Al}$ on the surface of Implant II (Table 1). $\mathrm{Pb}$ was not detected. EDS spectra provided similar information regarding the qualitative composition of the implants (Figure 5).

\section{Osteoblastic cytocompatibility Cell adhesion and proliferation}

Human osteoblastic bone marrow cells were cultured

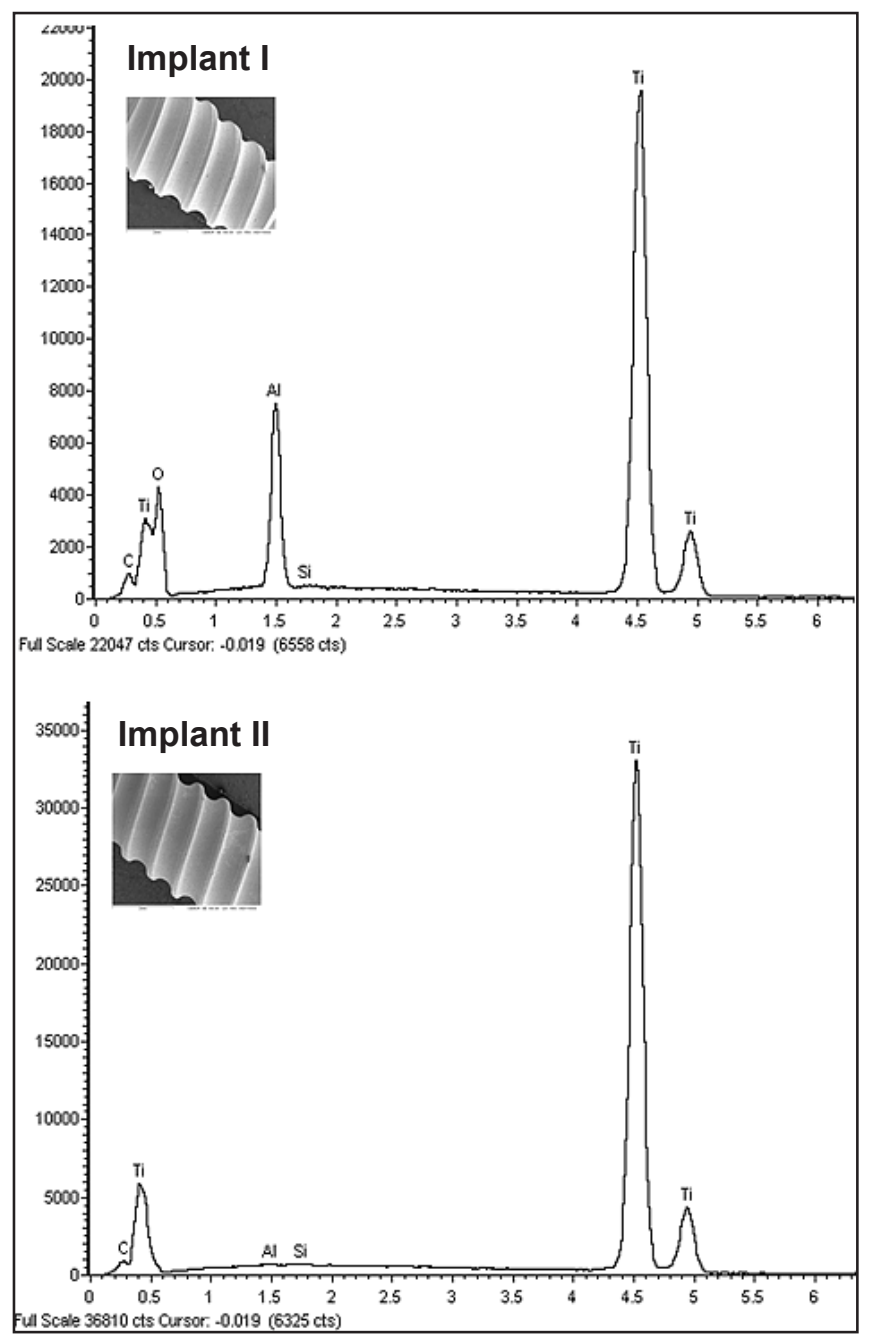

Figure 5. EDS spectra of the threaded regions of Implants I and II, with the typical Ti peaks. Compared to Implant I, Implant II did not show the Al peak. over the surface of the implants, and the colonized implants were characterized for proliferation and differentiation events (Figures 6 - 8). In both implants, low magnification SEM images (Figure 6A, B) showed adhered cells $3 \mathrm{~h}$ after plating, whereas at high magnification (Figure 6C, D), cells exhibited a round central shape with long cytoplasmic extensions and were able to adapt to the underlying irregular surface topography. At day 28, SEM images showed that the implants' surface was completely covered by a cell layer (Figure 6E, F). However, a thicker cell layer

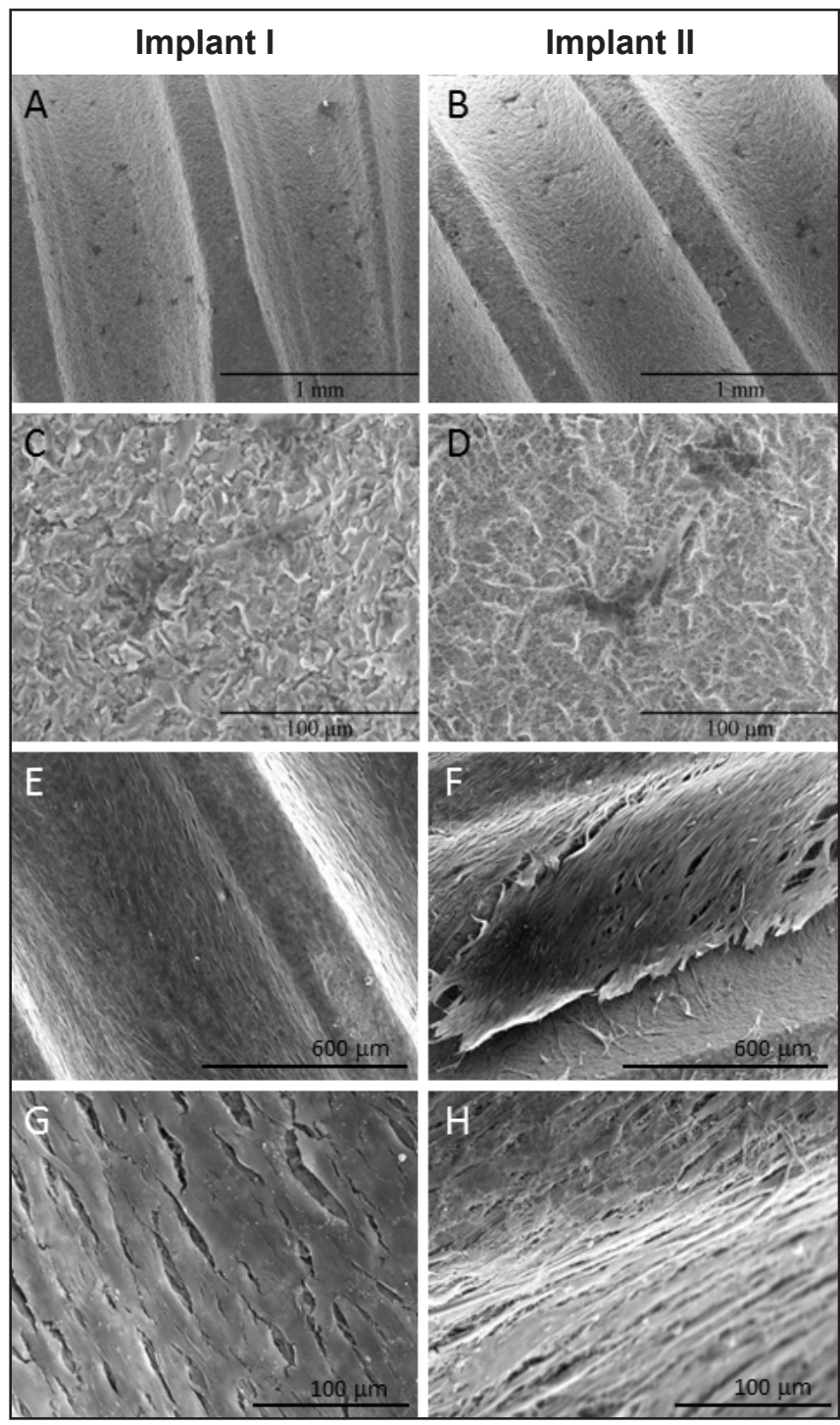

Figure 6. SEM images of Implants I and II colonized with human bone marrow osteoblastic cells. A - D = cell adhesion $3 \mathrm{~h}$ after cell plating. $\mathrm{E}-\mathrm{H}=$ appearance of the colonized implants at day 28 . Cell adhesion: $3 \mathrm{~h}$ after plating, cells are seen as darker points on the implant surface at low magnification (A, B); at a high magnification $(\mathrm{C}, \mathrm{D})$, cells showed a central area and cytoplasmic extensions which adapted to the underlying rough surface. At day 28, the implants surface was completely covered by a cell layer as seen in low magnification images (E, F), and Implant II showed a thicker cell layer; at a higher magnification, Implant I showed a continuous cell layer, whereas Implant II exhibited a fibrilar cell layer reflecting a more complex organization. 
was seen over Implant II; in addition, the cell layer exhibited a more complex organization with a fibrilar matrix, compared with that observed over ImplantI, which showed mostly a continuous cell layer (Figure 6G, H).

\section{Alkaline phosphatase (ALP) activity}

The time-dependent ALP activity, normalized to the total protein content (Figure 7), showed an increase with culture time in both colonized implants. ALP activity was higher over Implant II, attaining a statistically significant difference at day 21 ; in addition, maximum values were observed earlier, at day 21 , compared to colonized Implant I (maximal values, at day 28).

\section{Matrix mineralization}

SEM images of 28-day colonized implants showed the presence of mineralized globular deposits in close association with the cell layer in both implants, but the cell layer growing over Implant II exhibited a more complex fibrilar structure and a higher abundance of the globular structures (Figure 8A, B). Figure 8C shows a representative high magnification image of the mineralized deposits integrated in the fibrilar matrix, and Figure 8D displays the X-ray spectrum of the globular deposits, showing the presence of $\mathrm{Ca}$ and $\mathrm{P}$ peaks.

$\mathrm{Ca}_{\mathrm{i}}$ levels in the culture medium (Figure 8E) were relatively constant until approximately day 21 (Implant I) and day 16 (Implant II), decreasing significantly afterwards.

\section{DISCUSSION}

It is well established that surface topography of $\mathrm{Ti}$ implants is of particular interest for the osseointegration process, especially within the areas confined by single threads that are representative of the implants microtopography. This study compares two sandblasted and acid-etched implant systems, from Eckermann Laboratorium S.L. (Alicante, Spain). According to the manufacturer, the system patented as Eckcyte ${ }^{\mathbb{B}}$ (Implant II) has improved surface properties compared to the Implant system I, launched previously.

Implants I and II presented a similar geometry, namely thread spacing, distance peak-valley and valley shape. However, they exhibited a distinct microtopography, which was produced by sandblasting with $\mathrm{Al}_{2} \mathrm{O}_{3}$ followed by an etching process involving $\mathrm{HCl}, \mathrm{H}_{2} \mathrm{SO}_{4}$ and $\mathrm{HF}$ solutions, differing on the experimental protocols. In the acid-etched process, factors such as acid concentration, relative proportions of the acids used,

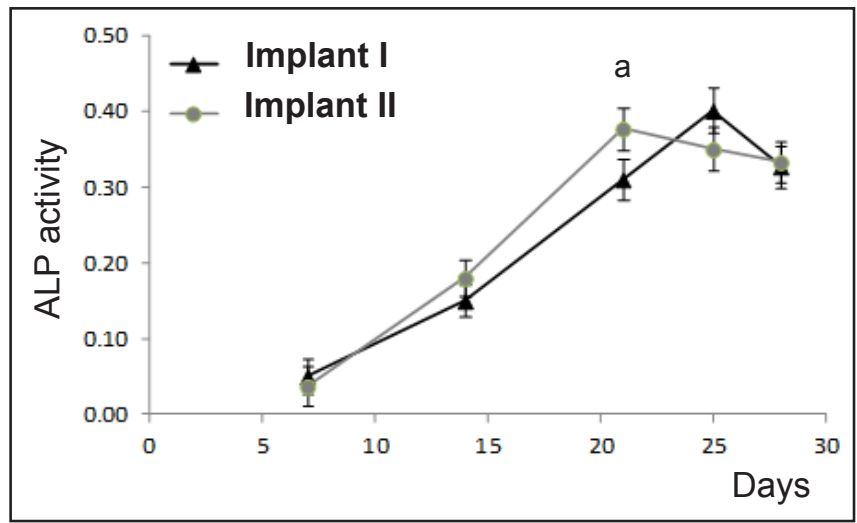

Figure 7. ALP activity, expressed as $\mathrm{nmol} / \mathrm{min}$.mMprotein, of human bone marrow osteoblastic cells grown over Implants I and II for 28 days. ALP activity increased throughout the culture time, and colonized Implant II exhibited earlier maximal values, compared to colonized Implant I.

${ }^{a}$ Significantly different from Implant I.

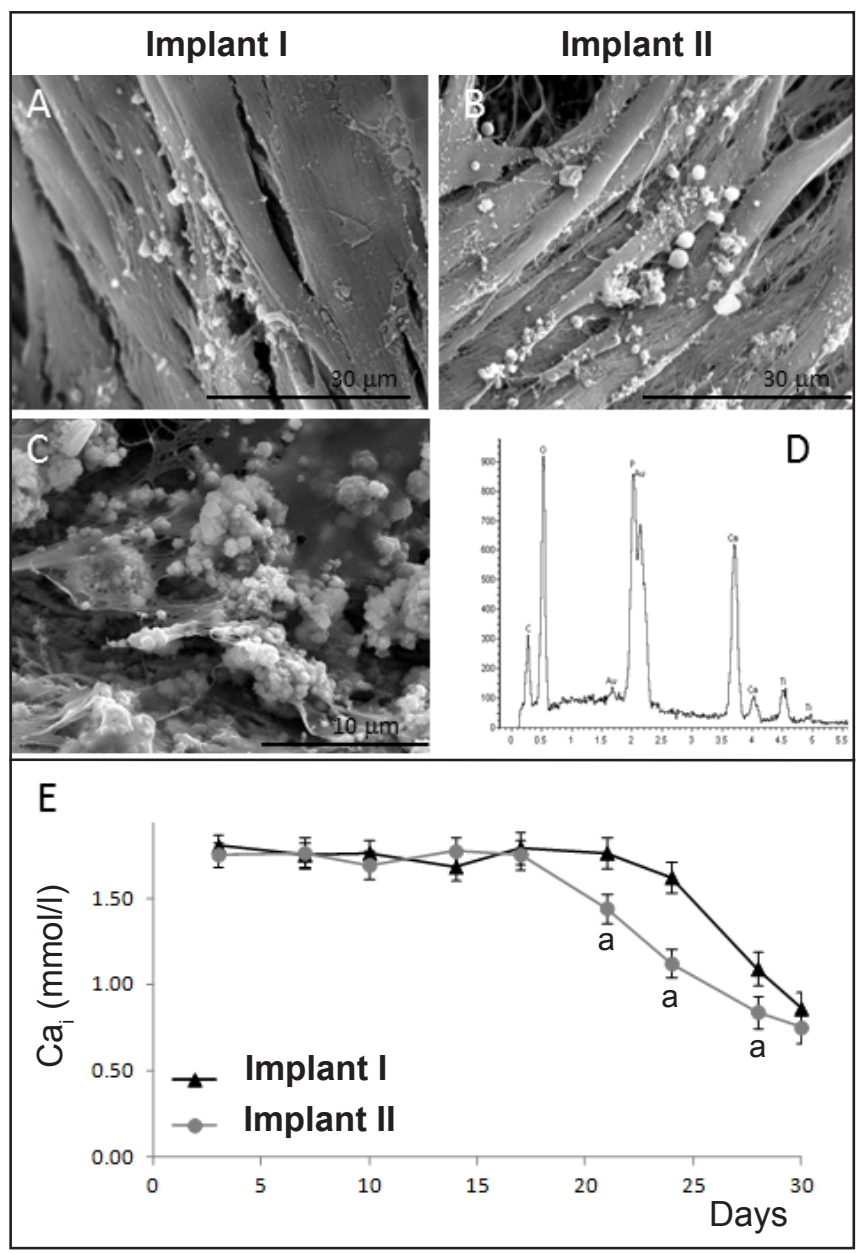

Figure 8. Matrix mineralization of human bone marrow osteoblastic cell cultures grown over Implants I and II for 28 days. High magnification SEM images: A, B and $\mathrm{C}=$ formation of globular mineralized structures closely associated with the cell layer. $\mathrm{D}=$ representative $\mathrm{X}$-ray spectra of the mineralized deposits, showing the presence of $\mathrm{Ca}$ and $\mathrm{P}$ peaks. $\mathrm{E}=$ levels of ionized calcium $\left(\mathrm{Ca}_{\mathrm{i}}\right)$ in the culture medium throughout the 30-day culture time, showing the consumption of $\mathrm{Ca}_{\mathrm{i}}$ from the medium due to the formation of calcium containing deposits in the cell layer.

${ }^{a}$ Significantly different from Implant I. 
temperature and time of exposure are variables that are worked out to create different topographies [3] . A variety of studies reported that specific acid-etching protocols produce microporous on $\mathrm{Ti}$ surfaces with sizes ranging from 0.5 to $4 \mu \mathrm{m}$ in diameter $[\underline{3}, \underline{8}]$, which appear similar to that seen on the surface of Implant II. This type of microporous surface has been shown to greatly improve osseointegration $[\underline{3}, \underline{19}]$. Regarding the different surface features of Implants I and II, a previous work performed in our laboratory, in titanium surfaces submitted to different acid-etching protocols, showed that etching treatments based mostly on $\mathrm{H}_{2} \mathrm{SO}_{4}$ solutions provided a surface with a topography similar to that seen on Implant I, and treatments with HF based solutions were very effective in smoothing irregular rough titanium surfaces creating an homogeneous rough topography [20]. Ti is very reactive to fluoride ions, forming soluble $\mathrm{TiF}_{4}$ species, and it is reported that this type of treatment creates a microrough topography and, also, fluoride incorporation, that appears to enhance osteoblastic differentiation [21] and osseointegration in in vivo experimental studies [22]. However, these considerations are merely speculative in which concerns the conditions used to produce the topography of Implants I and II, because such details were not disclosed by the manufacturer.

The surface of the tested implants differs also on amplitude, spacing and hybrid roughness parameters, as expected from their different topography. The average surface roughness (Ra) was higher on Implant II, compared to Implant I. However, the Ra values of both systems are within the range considered to yield improved implant performance [5]. It is worth mentioning that Ra gives only a good overall description of height variations (as it is the arithmetic average of the absolute deviations from the mean line over a sampling length), and it is not sensitive to small changes in the surface profile [23]. There are other parameters that complement surface description [23]. $\mathrm{Rz}$, the arithmetic average of the five highest profile peaks and the five lowest profile valleys over the entire measurement trace, was higher on Implant II. The same was observed for Rt, the maximum peak to valley of the entire measurement trace, and for Rsm, the arithmetic average spacing between the falling flanks of the peaks on the mean line measured over the sampling length. However, Implants I and II have similar Rku values, a parameter that describes the probability density sharpness of the profile. On the other hand, Rsk, defined as skewness, which measures the symmetry of the deviation from a mean plan, was more negative on Implant II than on Implant I, meaning that, comparatively, Implant II has more valleys than peaks, which is in line with that observed on the high magnification SEM images. Also, the three-dimensional topography images showed evidence of a more homogeneous rough surface on Implant II.

The chemical composition and changes on the surface of Ti implants differ, depending on their bulk composition and surface treatments. These are relevant issues as they affect the initial biological behaviour following implantation, such as protein adsorption and cell attachment, conditioning the subsequent proliferation and differentiation of bone cells at the implant surface []ㅡ. The present results showed that Implants I and II presented some differences in the chemical composition of the surface. XPS analysis revealed the presence of Ti, but also $\mathrm{O}, \mathrm{C}$ and $\mathrm{N}$, as expected, as these elements are commonly adsorbed on Ti surface [ $\underline{3}$ ]. The Ti $2 p$ doublet and the $\mathrm{O} 1 \mathrm{~s}$ peak reflected of titanium oxide $\left(\mathrm{TiO}_{2}\right)$ layer [3] , and the $\mathrm{C}$ peak indicates an organic contamination (presence of a carbon overcoat on the implant) that is normally associated with implant handling (during packaging, for example) [24]. Al $2 p$ peak is due to alumina residual particles on the surface, resulting from the blasting process with $\mathrm{Al}_{2} \mathrm{O}_{3}$. Alumina is insoluble in acid and is hard to remove from the Ti surface. These particles might be released into the surrounding tissues and cause deleterious effects on the implant osseointegration [ $[3]$. Also, the chemical heterogeneity of the implant surface may decrease the excellent corrosion resistance of $\mathrm{Ti}$ in physiological environment [25]. Implant II showed significantly lower levels of Al, suggesting differences on the blasting and/ or the acid-etching protocols. Regarding this, a previous work reported that HF solutions were more effective than $\mathrm{H}_{2} \mathrm{SO}_{4}$ solutions in eliminating $\mathrm{Al}$ contamination arising from the blasting process [20]. The implants presented also residual amounts of $\mathrm{F}$, resulting from the presence of HF in the acid-etching treatment. Si, $\mathrm{P}$ and $\mathrm{Ca}$ were found in very low levels, reflecting an inorganic contamination, normally associated with implant handling, as referred above [24]. It should be noted that the organic and inorganic pollution normally found on the implant surface is typically inhomogeneous across the implant, and should not be mistaken for controlled chemical or biochemical modifications [24]. Implant osseointegration requires the recruitment of osteoprogenitor cells and their proliferation and differentiation into functional osteoblasts that are able to produce a mineralized extracellular matrix at the interface. Bone cells can recognize and respond to substratum structures both in vivo and in vitro [3] , and, in the present work, human bone marrow cells, cultured in experimental conditions that favour osteoblastic differentiation [26,27], were seeded over Implants I and II, and the colonized implants were evaluated for the elicited cell response. Results showed that both 
implants allowed the initial cell adhesion and spreading and the subsequent cell proliferation, as assessed by SEM observation at an early (3h) and a later ( 28 days) culture time. In addition, ALP activity increased significantly during the culture time, suggesting an osteoblastic differentiation pathway [26]. ALP has a determinant role in the onset of the matrix mineralization, by providing phosphate ions from the hydrolysis of organic phosphates (in vitro, from the added $\beta$-glycerophosphate) that, together with calcium ions (in vitro, present in the culture medium), are used in the formation of the cell mediated calcium phosphate mineralized matrix. Accordingly, 28-day colonized implants showed the presence of calcium phosphate deposits, closely associated with the cell layer, as observed by SEM and coupled EDS. Concentration of $\mathrm{Ca}_{\mathrm{i}}$ in the culture medium was determined throughout the culture time, in order to get information on the time-dependent profile of the mineralization process. The measured $\mathrm{Ca}_{\mathrm{i}}$ levels reflected changes occurring between every medium change, so that the values were not cumulative. The decreased $\mathrm{Ca}_{\mathrm{i}}$ levels observed at later culture times reflected the consumption of $\mathrm{Ca}_{\mathrm{i}}$ from the culture medium, that is being used in the formation of calcium phosphate deposits in the collagenous matrix. Matrix mineralization is the last event of the osteoblast differentiation, and the observed behaviour is representative of the in vivo osteoblast phenotype [26]. This cell response is expected, as it is in agreement with the known biocompatibility of $\mathrm{Ti}[\underline{3}]$, and also considering that the surface roughness of both implants is within the range reported to provide a good biological performance [2]. Compared to Implant I, Implant II showed a thicker fibrilar cell layer, an earlier peak of ALP activity and onset of matrix mineralization (as evident by the time-profile of the $\mathrm{Ca}_{\mathrm{i}}$ consumption) and a more abundant mineralized matrix. The better performance of Implant II is related to its surface properties, and surface microtopography certainly plays an essential role in this behaviour. Homogeneous rough microporous surfaces are reported to promote the adhesion of fibrin improving the osteoconductivity and providing contact guidance for the osteogenic cells migrating along the implant surface, compared to irregularly rough surfaces $[\underline{3}, \underline{28}]$. Also, this type of surface topography appears to provide a higher bone-to-implant contact, as described in in vivo studies $[9,10]$. Some differences were also observed on the surface chemical composition, and this might also affect biological response [ [ $]$. It is worthwhile to note that, as referred above, Implant II contains a significantly lower percentage of Al, which is a positive feature, considering the deleterious effects of this element on cell behaviour [3].

The main limitation of this study is the lack of information in commercial or scientific literature on the details of the manufacturing process of the two implant systems, which is not surprising as it is a trade secret of the manufacturer. Thus, it is not possible to correlate specific surface properties with the observed osteoblastic cell response. Nevertheless, the homogeneous rough surface microtopography of Implant II fills many of the features reported to contribute to an improved bone cell response and better clinical outcome, as referred above.

\section{CONCLUSIONS}

Implants I and II presented a similar geometry, but a distinct microtopography, and also some differences in the surface roughness parameters and chemical composition. However, the homogeneous rough and microporous surface of Implant II is most probably a main factor for its improved oteoblastic performance, reflected by the presence of a thicker fibrilar cell layer and an earlier and more abundant matrix mineralization. The lower Al content of Implant II also deserves to be noted, due to the known cytotoxicity of this element. The earlier osteoblastic differentiation that appears to occur on Implant II might be a relevant factor during the first stages of bone apposition, which in turn may speed up and enhance the osseointegration process anticipating a better clinical outcome.

\section{ACKNOWLEDGMENTS AND DISCLOSURE STATEMENTS}

This study was supported by Faculdade de Medicina Dentária da Universidade do Porto. The tested implants were kindly provided by Eckermann Laboratorium S.L. (Alicante, Spain). The authors report no conflicts of interest related to this study.

\section{REFERENCES}

1. Esposito M, Coulthard P, Thomsen P, Worthington HV. The role of implant surface modifications, shape and material on the success of osseointegrated dental implants. A Cochrane systematic review. Eur J Prosthodont Restor Dent. 2005 Mar;13(1):15-31. Review. [Medline: 15819145]

2. Albrektsson T, Wennerberg A. The impact of oral implants - past and future, 1966-2042. J Can Dent Assoc. 2005 May;71(5):327. [Medline: 15949251] 
3. Le Guéhennec L, Soueidan A, Layrolle P, Amouriq Y. Surface treatments of titanium dental implants for rapid osseointegration. Dent Mater. 2007 Jul;23(7):844-54. Epub 2006 Aug 14. Review. [Medline: 16904738] [doi: 10.1016/j.dental.2006.06.025]

4. Wennerberg A, Albrektsson T. Suggested guidelines for the topographic evaluation of implant surfaces. Int J Oral Maxillofac Implants. 2000 May-Jun;15(3):331-44. [Medline: 10874798]

5. Albrektsson T, Wennerberg A. Oral implant surfaces: Part 1--review focusing on topographic and chemical properties of different surfaces and in vivo responses to them. Int J Prosthodont. 2004 Sep-Oct;17(5):536-43. [Medline: 15543910]

6. Albrektsson T, Wennerberg A. Oral implant surfaces: Part 2--review focusing on clinical knowledge of different surfaces. Int J Prosthodont. 2004 Sep-Oct;17(5):544-64. Review. [Medline: 15543911]

7. Albrektsson T. Is surgical skill more important for clinical success than changes in implant hardware? Clin Implant Dent Relat Res. 2001;3(4):174-5. [Medline: 11887653] [doi: 10.1111/j.1708-8208.2001.tb00138.x]

8. Zinger O, Anselme K, Denzer A, Habersetzer P, Wieland M, Jeanfils J, Hardouin P, Landolt D. Time-dependent morphology and adhesion of osteoblastic cells on titanium model surfaces featuring scale-resolved topography. Biomaterials. 2004 Jun;25(14):2695-711. [Medline: 14962549] [doi: 10.1016/j.biomaterials.2003.09.111]

9. Novaes AB Jr, Papalexiou V, Grisi MF, Souza SS, Taba M Jr, Kajiwara JK. Influence of implant microstructure on the osseointegration of immediate implants placed in periodontally infected sites. A histomorphometric study in dogs. Clin Oral Implants Res. 2004 Feb;15(1):34-43. [Medline: 14731175] [doi: 10.1046/j.1600-0501.2003.00968.x]

10. Papalexiou V, Novaes AB Jr, Grisi MF, Souza SS, Taba M Jr, Kajiwara JK. Influence of implant microstructure on the dynamics of bone healing around immediate implants placed into periodontally infected sites. A confocal laser scanning microscopic study. Clin Oral Implants Res. 2004 Feb;15(1):44-53. [Medline: 14731176] [doi: 10.1111/j.1600-0501.2004.00995.x]

11. Shalabi MM, Gortemaker A, Van't Hof MA, Jansen JA, Creugers NH. Implant surface roughness and bone healing: a systematic review. J Dent Res. 2006 Jun;85(6):496-500. Review. Erratum in: J Dent Res. 2006 Jul;85(7):670. [Medline: 16723643] [doi: 10.1177/154405910608500603]

12. Wennerberg A, Albrektsson T, Andersson B, Krol JJ. A histomorphometric and removal torque study of screwshaped titanium implants with three different surface topographies. Clin Oral Implants Res. 1995 Mar;6(1):24-30. [Medline: 7669864]

13. Becker W, Becker BE, Ricci A, Bahat O, Rosenberg E, Rose LF, Handelsman M, Israelson H. A prospective multicenter clinical trial comparing one- and two-stage titanium screw-shaped fixtures with one-stage plasma-sprayed solid-screw fixtures. Clin Implant Dent Relat Res. 2000;2(3):159-65. [Medline: 11359261] [doi: 10.1111/j.1708-8208.2000.tb00007.x]

14. Masaki C, Schneider GB, Zaharias R, Seabold D, Stanford C. Effects of implant surface microtopography on osteoblast gene expression. Clin Oral Implants Res. 2005 Dec;16(6):650-6. [Medline: 16307571] [doi: 10.1111/j.1600-0501.2005.01170.x]

15. Schwartz Z, Nasazky E, Boyan BD. Surface microtopography regulates osteointegration: the role of implant surface microtopography in osteointegration. Alpha Omegan. 2005 Jul;98(2):9-19. [Medline: 16122142]

16. Jäger M, Zilkens C, Zanger K, Krauspe R. Significance of nano- and microtopography for cell-surface interactions in orthopaedic implants. J Biomed Biotechnol. 2007;2007(8):69036. [Medline: 18274618] [doi: 10.1155/2007/69036] [FREE Full Text]

17. Schneider GB, Zaharias R, Seabold D, Keller J, Stanford C. Differentiation of preosteoblasts is affected by implant surface microtopographies. J Biomed Mater Res A. 2004 Jun 1;69(3):462-8. [Medline: 15127393] [doi: 10.1002/jbm.a.30016]

18. Hansson S, Norton M. The relation between surface roughness and interfacial shear strength for boneanchored implants. A mathematical model. J Biomech. 1999 Aug;32(8):829-36. [Medline: 10433425] [doi: 10.1016/S0021-9290(99)00058-5]

19. Wong M, Eulenberger J, Schenk R, Hunziker E. Effect of surface topology on the osseointegration of implant materials in trabecular bone. J Biomed Mater Res. 1995 Dec;29(12):1567-75. [Medline: 8600147] [doi: 10.1002/jbm.820291213]

20. Diniz MG, Soares GA, Coelho MJ, Fernandes MH. Surface topography modulates the osteogenesis in human bone marrow cell cultures grown on titanium samples prepared by a combination of mechanical and acid treatments. J Mater Sci Mater Med. 2002 Apr;13(4):421-32 [Medline: 15348619] [doi: 10.1023/A:1014357122284]

21. Cooper LF, Zhou Y, Takebe J, Guo J, Abron A, Holmén A, Ellingsen JE. Fluoride modification effects on osteoblast behavior and bone formation at $\mathrm{TiO} 2$ grit-blasted c.p. titanium endosseous implants. Biomaterials. 2006 Feb;27(6):92636. Epub 2005 Aug 19. [Medline: 16112191] [doi: 10.1016/j.biomaterials.2005.07.009]

22. Ellingsen JE, Johansson CB, Wennerberg A, Holmén A. Improved retention and bone-tolmplant contact with fluoride-modified titanium implants. Int J Oral Maxillofac Implants. 2004 Sep-Oct;19(5):659-66. 2004;19:659-66. [Medline: 15508981$]$

23. Muralikrishnan B, Raja J. Surface finish parameters I: Amplitude, spacing, hybrid and shape. In: Muralikrishnan B, Raja J, editors. Computational surface and roundness metrology. London: Springer-Verlag London Limited; 2009. p. 181-190.

24. Morra M, Cassinelli C, Bruzzone G, Carpi A, Di Santi G, Giardino R, Fini M. Surface chemistry effects of topographic modification of titanium dental implant surfaces: 1. Surface analysis. Int J Oral Maxillofac Implants. 2003 JanFeb;18(1):40-5. [Medline: 12608667] 
25. Aparicio C, Gil FJ, Fonseca C, Barbosa M, Planell JA. Corrosion behaviour of commercially pure titanium shot blasted with different materials and sizes of shot particles for dental implant applications. Biomaterials. 2003 Jan;24(2):263-73. [Medline: 12419627] [doi: 10.1016/S0142-9612(02)00314-9]

26. Aubin J. Mesenchymal stem cell and osteoblast differentiation. In: Bilezikian JP, Raisz LG, Martin TJ, editors. Principles of bone biology. Toronto: Academic Press; 2008. p. 85-107. [doi: 10.1016/B978-0-12-373884-4.00026-4]

27. Coelho MJ, Fernandes MH. Human bone cell cultures in biocompatibility testing. Part II: effect of ascorbic acid, betaglycerophosphate and dexamethasone on osteoblastic differentiation. Biomaterials. 2000 Jun;21(11):1095-102. [Medline: 10817261] [doi: 10.1016/S0142-9612(99)00192-1]

28. Zhao G, Zinger O, Schwartz Z, Wieland M, Landolt D, Boyan BD. Osteoblast-like cells are sensitive to submicron-scale surface structure. Clin Oral Implants Res. 2006 Jun;17(3):258-64. [Medline: 16672020] [doi: 10.1111/j.1600-0501.2005.01195.x]

\section{To cite this article:}

Mesquita P, Gomes PD, Sampaio P, Juodzbalys G, Afonso A, Fernandes MH. Surface Properties and Osteoblastic Cytocompatibility of Two Blasted and Acid-Etched Titanium Implant Systems with Distinct Microtopography.

J Oral Maxillofac Res 2012;3(1):e4

URL: http://www.ejomr.org/JOMR/archives/2012/1/e4/v3n1e4ht.pdf

doi: $10.5037 /$ jomr.2012.3104

Copyright (C) Mesquita P, Gomes PD, Sampaio P, Juodzbalys G, Afonso A, Fernandes MH. Accepted for publication in the JOURNAL OF ORAL \& MAXILLOFACIAL RESEARCH (http://www.ejomr.org), 29 March 2012

This is an open-access article, first published in the JOURNAL OF ORAL \& MAXILLOFACIAL RESEARCH, distributed under the terms of the Creative Commons Attribution-Noncommercial-No Derivative Works 3.0 Unported License, which permits unrestricted non-commercial use, distribution, and reproduction in any medium, provided the original work and is properly cited. The copyright, license information and link to the original publication on (http://www.ejomr.org) must be included. 